\title{
3D seismic evidence of internal structure within Tampen Slide deposits on the North Sea Fan. Are chaotic deposits that chaotic?
}

\author{
Gafeira, J. ${ }^{1,2}$, Long, $D .{ }^{1}$, Scrutton, R. $^{2} \&$ Evans, $D .^{1}$ \\ ${ }^{1}$ British Geological Survey, Murchison House, West Mains Rd., EH9 3LA, Edinburgh, UK \\ ${ }^{2}$ Department of Geology and Geophysics, Grant Institute, University of Edinburgh, Edinburgh, Scotland
}

\begin{abstract}
The seismic character of slide deposits is typically described as structureless or chaotic. However, 3D seismic data from the northern flank of the North Sea Fan reveal recognizable internal, penetrative structures within the Tampen Slide deposits. The study of its seismic attributes allowed an integrated characterization of the slide deposits and has shown distinctive acoustic fabrics, both at the top and base of the slide deposit, which are interpreted to be the expression of internal deformation structures. Based on their geometry, four main seismic fabric types have been defined: anastomosing, curvilinear, rectilinear and wispy. The spatial distribution of the fabric was mainly controlled by a topographic high present on the seabed at the time of the gravitational collapse, which influenced the transport of material. Areas of distinct fabrics are thought to reflect different flow behaviour during the latest stages of the mass movement and could be considered kinematic indicators. The results give new insights into the transport and deformation processes of submarine mass movements and highlight the potential of detailed analysis of 3D seismic data.
\end{abstract}

Like many continental slopes around the world where rapid sedimentation has occurred the North Sea Fan at the mouth of the Norwegian Channel includes multiple deposits of gravitational collapses. These have occurred periodically since the late Pliocene, with the most recent known as the Tampen Slide (King et al. 1996). The primary tool to describe and characterize these types of large buried deposits is 2D seismic profiling. This frequently leads to these deposits being described as chaotic or structureless to distinguish them from the reflector-rich sedimentary sequences from which they are derived. However, interpretation of 3D seismic data reveals that the Tampen Slide deposits are far from having structureless or chaotic acoustic internal character. 3D seismic data have proven to be a valuable source of information for the study of submarine gravitational collapses (e.g. Huvenne et al. 2002; Gee et al. 2005; Frey-Martinez et al. 2006; Gafeira et al. 2007), contributing to narrow the gap between the knowledge acquired from geophysical data and the knowledge derived from the direct observation of outcrop of ancient collapse deposits. Although the features presented here are specific to the study area, the ideas and principles have a broader application to the understanding of gravitational collapse deposits. This paper also highlights the potential of detailed studies of slide deposits using 3D seismic data.

\section{Geological Setting}

The North Sea Fan covers an area of approximately 142,000 km² (King et al. 1996), and is one of the largest trough-mouth fans on the glaciated European Margin (Vorren \& Laberg 1997). This trough-mouth fan is located on the SE Nordic Sea margin (Fig. 1), between the Storegga Slide depression and the Færøe-Shetland Channel $\left(3^{\circ} \mathrm{E}-4^{\circ} \mathrm{W}\right)$. The fan stretches seaward from the mouth of the Norwegian Channel in the northern North Sea up to the extinct Ægir Ridge spreading axis (Nygård et al. 2005), starting at water depths around $400 \mathrm{~m}$ and reaching more than 3600 m depth. King et al. (1996) described the North Sea Fan as a large progradational wedge of glacigenic sediments and Nygård et al. (2005) sub-divided it into two provinces separated by the volcanic Møre Marginal High. The study area for this paper is located within the proximal fan province of Nygård et al. (2005), which is characterised by evidence of alternation between episodes of deposition, mainly of glaciogenic debris flow deposits (GDFs), and erosion, by large-scale gravitational collapses.

These large-scale events have occurred on the North Sea Fan since the start of the PlioPleistocene glacial-interglacial cycles (Bryn et al. 2003; Evans et al. 2005). The Tampen Slide is 
one of the largest of these collapses. With an area of at least $15000 \mathrm{~km}^{2}$ it involved more than $3000 \mathrm{~km}^{3}$ of sediment (Evans et al. 1996). This slide removed from the North Sea Fan a large part of the glaciogenic debris flow deposits of the Saalian glacial period (MIS 6), which can be up to $400 \mathrm{~ms}$ thick on the western section of the North Sea Fan (Nygård et al. 2005). The smooth upper surface of an older sequence of glaciogenic debris flow deposits, possibly draped with MIS 7 interglacial sediments, may have acted as a sliding surface for the Tampen Slide (Sejrup et al. 2004). Additionally, Nygård et al. (2005) suggested that the resistance to erosion of the MIS 8 glaciogenic debris flow deposits by the Tampen Slide might be attributed to consolidation before the Tampen Slide event. The Tampen Slide's $200 \mathrm{~km}$-long headwall was totally buried by glaciomarine sedimentation and later glaciogenic debris flow deposits, despite being locally over $200 \mathrm{~m}$ high (Evans et al. 1996). The eastern sidewall of the Tampen Slide, as well as part of the headwall, was truncated by the Holocene Storegga Slide. Therefore, the known dimensions of the Tampen Slide represent most likely to minimum values. The study area is located within the area of sediment removal by the Tampen Slide, approximately $65 \mathrm{~km}$ downslope from its headwall (Fig. 1).

\section{Database}

The main data source for this study consists of a commercial 3D seismic data volume from the mid-Norwegian continental margin provided by StatoilHydro (Fig. 1). This 3D seismic volume (Tulipan) was acquired in 2001 and covers an area of $1618 \mathrm{~km}^{2}$, in water depth ranging from 1310 to $1830 \mathrm{~m}$ deep. The 16-bit unclipped full-offset volume used had negative polarity, meaning that an increase in acoustic impedance is displayed as a trough. The dominant frequency of the seismic data varies with depth, and is approximately $35 \mathrm{~Hz}$ at the levels of interest, yielding a vertical resolution of approximately $11 \mathrm{~m}(\lambda / 4)$ assuming an average velocity of $1522 \mathrm{~ms}^{-1}$, a velocity based on unpublished well data. The final bin spacing of the seismic grid is $12.5 \mathrm{~m} \times 12.5 \mathrm{~m}$ defining a grid with 6400bin cells per $\mathrm{km}^{2}$ after processing.

Additionally, data acquired during the Seabed Project and the Ormen Lange Project as part of the Norwegian Deepwater Program (NDP), together with bathymetric data from the North Sea Fan for the SEA4 Project and 2D seismic profiles (single and multi-channel), both of which were acquired by the British Geological Survey (BGS), were also made available for this study. These data sets provided a regional perspective of the area and a context to the detailed study of the $3 \mathrm{D}$ data.

\section{Methodology}

Key reflectors, which best describe the study area and that could be related to the established regional seismic stratigraphy (King et al. 1996 and Nygård et al. 2005), were recognised on the 2D seismic lines and identified on the 3D seismic data. These reflectors were picked manually on reference vertical sections and then propagated throughout the rest of the volume using SeisWorks's ZAP! ${ }^{\mathrm{TM}}$ autopicking software, from Landmark Graphics Corporation. Based on the analysis of the generated surface's confidence map, problematic areas with erroneous autopicking were identified. These areas were then manually re-picked and more accurate autopicking obtained. Iterative manual re-picking was required in some cases to obtain satisfactory results. Several amplitude maps were extracted from final picked key reflectors. To avoid the overlap of information related to variations of acoustic properties within the material above and below the reflector, several horizons were generated at a constant interval from the picked reflector. The amplitude map of a horizon, for instance, $8 \mathrm{~ms}$ above a key reflector will only show acoustic-impedance changes within the overlying material, allowing a clearer display and a better understanding of its internal structures (Fig. 2). The vertical displacement applied to generate these horizons varied from 5 to $15 \mathrm{~ms}$ and was defined by the individual and detailed observations of the waveform response near the key reflector. In addition, amplitude maps and root-mean-square (RMS) amplitude maps were also generated from time windows above or 
below these horizons. These windowed amplitude maps provide useful information for the internal structure.

Each of the generated horizon surfaces and their respective seismic attributes were exported to the Geographic Information Systems (GIS) package ArcGIS ${ }^{\mathrm{TM}}$. Additionally, several time-slices were also extracted and built into the GIS allowing an integrated display of data. Spatial analysis tools were used to produce slope and hillshade maps of the extracted horizon's surfaces. Display options offered by the software, such as the 3-D visualization of seismic attributes draped on top of the respective horizon's Digital Elevation Model (DEM) surface, were particularly useful for detailed geomorphologic characterisation. In order to determine thicknesses in metres and to calculate slope values, the assumed velocity of $1522 \mathrm{~ms}^{-1}$ for the levels of interest was used for the approximate depth conversion.

\section{Seismic units}

The seismic units here describe are part of the Naust formation $(0-2.8 \mathrm{Ma})$, dominated by the development of thick prograding sediment wedges along the North Sea Fan and Vøring region (Dahlgren et al. 2005). The nomenclature proposed for the Naust Formation in the Seabed Project was adopted in this work, where this Late Pliocene-Pleistocene formation is subdivided into five seismic regional sequences from oldest to youngest: $\mathrm{N}, \mathrm{A}, \mathrm{U}, \mathrm{S}$ and $\mathrm{T}$ (Norwegian Deepwater Programme 2004).

Five main seismostratigraphic units, Unit I (youngest) to Unit V (oldest), were identified in this study (Fig. 3). The definition of the seismic units was based on the identification of packages with distinctive seismic facies, separated by strong and laterally-continuous key reflectors, building upon previous studies of the North Sea Fan area by King et al. $(1996,1998)$ and Nygård et al. (2005). Figure 4 presents the relation between the seismic units used in this study and sequences, defined by the authors mention above, and the key reflectors used. The Norwegian Deepwater Programme (2004) established a nomenclature for the key reflectors in the area which is followed here. They were either named after their regional stratigraphic meaning (e.g. TNS Top of Naust S) or the specific seismic unit boundary they represent (e.g. TTS - Top of Tampen Slide).

\section{Description}

The Tampen Slide deposits are easily recognised on seismic profiles as a seismic unit of chaotic to discontinuous seismic reflections - here designated as Unit II (Fig. 3 and 4). This unit is the most recognisable unit in the study area, and it is well defined by high-amplitude reflections that show a smoother base and irregular top (Fig. 3). These reflections mark the contrasting contact between the Tampen Slide deposits and the underlying and overlying seismic units. The strong, bright signal of the top of the Tampen Slide deposit reflector, reflector TTS, may represent the contrast between (1) the slide deposits and the material which settled out of suspension immediately after the slide, (2) the slide deposits and hemipelagic sediments that settled later, or perhaps (3) between the slide deposits and late-phase sliding generated in response to the radical new topography that had just been created. Whatever the nature of the overlying material, the irregular topography of the top of the deposit was preserved (Fig. 3).

The digital elevation model of the base of the Tampen Slide deposits together with the seismic profiles (Figs. 4 and 5) show that the basal surface of the Tampen Slide follows the top of Unit III for over $75 \%$ of the study area. Where Unit III is not present the slide overlies the Møre Topographic High (MTH). The Tampen Slide sliding surface passage from the top of Unit III to the top of the Møre Topographic High is marked by evident changes of surface morphology. On the Møre Topographic High area this surface presents higher slope values $\left(<5^{\circ}\right)$ compared to the typical values on surrounding areas $\left(<2^{\circ}\right)$. The steeper areas correspond to erosive features associated to the cauliflower-shaped headwall present at the northern side of the topographic high 
(Fig. 5). This headwall predate the Tampen Slide and it was partially buried by Unit III and IV deposits, however the Tampen Slide deposits overlay directly the $15 \mathrm{~km}$ wide, uppermost scar area characterised by radial ridges and multiple secondary erosional scar (Fig. 6).

The Tampen Slide deposits show significant variations of two-way travel time (TWT) thickness in the study area ranging from 40 to $180 \mathrm{~ms}$ thick (Fig. 7), circa 30 to $136 \mathrm{~m}$. Over an area of more than $40 \mathrm{~km}^{2}$ immediately southeast of the Møre Topographic High, the Tampen Slide deposits are more than $160 \mathrm{~ms}$ (c. $122 \mathrm{~m}$ ) thick. In contrast, above the Møre Topographic High the Tampen Slide deposits can be as thin as $50 \mathrm{~ms}$ (c. $38 \mathrm{~m})$. Nevertheless, it is on the western edge of the seismic volume that the thinnest deposits of Tampen Slide are found (40 ms; c. $30 \mathrm{~m})$.

The amplitude map for the reflector at the base of the Tampen Slide, TNS reflector, shows marked patterns of lower and higher amplitude values (Fig.2). However, its interpretation is challenging and confusing since it reflects changes of seismic response from the material both above and beneath the seismic reflector (Fig.2). The patterns are clearer on the amplitude map of horizon TNS-12ms (Fig. 8), which is a horizon $12 \mathrm{~ms}$ (TWT) above the reflector TNS. Therefore, this horizon allows the observation of lateral changes in the seismic response above, and only above, the reflector TNS, reflecting the seismic properties at near the base of the Tampen Slide deposit. The patterns of higher and lower amplitude values observed vary from area to area and, using this technique, it is possible to identify in map view four main fabrics (Fig. 8): a) Anastomosing fabric, b) Curvilinear fabric, c) Rectilinear fabric, and d) Wispy fabric.

The spatial analysis maps from the DEM of the TTS reflector shaded-relief map and slope map reveal that the irregular topography of the top of the Tampen Slide also presents a variety of textures (Fig. 9). Based on the configuration of these textures it is possible to identify the same four fabrics observed on the TNS-12ms amplitude map of the base of the Tampen Slide deposits. Each of these fabrics is illustrated and described in Figure 10.

Together, the amplitude map of the TNS-12ms horizon and the maps generated from the TTS reflector's DEM were used to divide the Tampen Slide deposits into seven fabric regions (A1, A2, B, C1, C2, D1 and D2), with each region dominated by one of the four main identified fabrics and surrounded by areas of higher complexity or undefined fabric (Fig. 11). In these surrounding areas the patterns observed tend to change gradually without clear boundaries, combining features from two or more of the main identified fabrics.

The Anastomosing fabric covers approximately one third of the study area and can be identified in two separated areas, A1 and A2 both (Fig. 11). The thickness of the slide deposits varies between 50 and $110 \mathrm{~ms}$ (c. 38 to $84 \mathrm{~m}$ ) where this fabric occurs. The Curvilinear fabric is found in the area B (Fig. 11), where the base of the Tampen Slide deposits are in direct contact with the top of the Møre Topographic High. Rapid changes in thickness are observed within this area, from $60 \mathrm{~ms}(\mathrm{c} .46 \mathrm{~m})$ to more than $140 \mathrm{~ms}($ c. $107 \mathrm{~m})$. The Rectilinear fabric occurs in two areas, C1 and C2 (Fig. 11), both south of the Møre Topographic High. No major thickness variations are observed within the areas. The Wispy fabric can be found immediately southeast of the Møre Topographic High in area D1, and up slope in D2 (Fig. 11), where the deposits are thicker than $150 \mathrm{~ms}$ (c. $114 \mathrm{~m})$.

The RMS amplitude maps from a sub-volume of $30 \mathrm{~ms}$ and $40 \mathrm{~ms}$ thickness at 25, 35, and $45 \mathrm{~ms}$ above the TNS reflector show that the distinctive fabrics at the top and base of the Tampen Slide deposits are the expression of the internal structures, which penetrate throughout the deposits. For illustration, a detail of the RMS amplitude map of the $30 \mathrm{~ms}$ window centred $40 \mathrm{~ms}$ above the base of the Tampen Slide deposits is presented in Figure 12. The internal structures can also be 
observed on the seismic lines featuring as discontinuities that are continuous throughout the thickness of the deposits, marked by strong amplitude variations at the base of the deposits and by less-marked variations at the top. These discontinuities tend to be coincident with topographic irregularities on the top of the Tampen Slide deposits (Fig. 12).

\section{Discussion}

Although the surface between the Tampen Slide deposits and the underlying Unit III does not exhibit recognisable erosion features, the base of the slide is thought to be an erosive surface developed during the mass movement (Sejrup et al. 2004). The smooth surface of the top of Unit III, which is composed mainly of glaciogenic debris flow deposits, acted as the sliding surface for the Tampen Slide. In the central part of the study area, the sliding surface of the Tampen Slide follows the top of Møre Topographic High (Figs. 3 and 6). Probably due to the higher degree of consolidation and/or to the presence of interglacial deposits draped on top of the Møre Topographic High, this topographic feature was not reshaped during the Tampen Slide event, preserving erosional features related to a previous episodes of slope instability (Fig. 6).

The spatial variations of thickness within the Tampen Slide deposits (Fig. 7) indicate that the relief of the Møre Topographic High influenced the distribution and thickness of material remoulded during the Tampen Slide event in the study area. The increase in thickness of this deposits immediately south-east of the Møre Topographic High and subsequent reduction above this topographic high is consistent with a mainly north-westward direction of transport. The thinning of these deposits westward of the Møre Topographic High can be interpreted as the response of an efficient transport of remoulded material away from the influence of the flow obstacle that the Møre Topographic High must have represented. Therefore, morphological changes on the Tampen's sliding surface may have also induced changes on the mass-flow behaviour, by diversion of the transport direction, and influencing the transport velocity.

The Tampen Slide deposits show several fabrics linked to the spatial configuration of penetrative acoustic discontinuities. These acoustic discontinuities create patterns of high- and low-amplitude (Fig. 8) that appear to be expressed in the morphology of the upper surface of the slide deposits (Fig. 9). Bull et al. (2009) examining the same 3D seismic data consider that these discontinuities correspond to the edges of disaggregated remnant blocks of material within the slide deposits and compare their seismic signature to the acoustic patterns identified by Huvenne et al. (2002) within the Porcupine/Magellan Slide deposits. However, that comparison may be questionable considering that the acoustic patterns found on the Tampen Slide are quite distinct from the ones shown by Huvenne et al. (2002). In the case of the Porcupine/Magellan Slide, the blocks do not present any apparent size, shape or orientation trend except on the toe area of the slide (Huvenne et al. 2002) whereas in our studied area the discontinuities define distinct organized fabrics showing evidence of continuity and gradual transition between the different fabrics. Additionally, these two deposits occur in very different settings. The Porcupine/Magellan Slide stopped at an early stage of development (Huvenne et al. 2002) and can be classified as a frontally confined slide in the sense of Frey-Martinez et al. (2006) due to characteristics such as limited displacement, whereas in the case of Tampen Slide the acoustic patterns described are found in the slide's translational section with marked sediment removal (Nygård et al. 2005).

Although the source of these acoustic discontinuities is still uncertain, they probably result from deformation structures developed during downslope translation of the remoulded material. A variety of deformation structures that include folds, boudinage, faults and sandstone dykes, have been described on outcrop of ancient gravitational collapse deposits (e.g. Strachan 2008). However, considering the scale of these penetrative discontinuities, we believe that they result from fractures developed throughout the remoulded material. After the fragmentation of the 
remobilized material and during the last stages of transport, the development of a degree of coherency probably occurred with the deceleration of the flow motion and dewatering of the material. At that stage, some amount of displacement could have been accommodated in a brittle manner, generating fractures that would induce the acoustic discontinuities observed on the seismic data.

According to this model of fabric generation, the developing fabric responds both to changes in the material rheological proprieties and changes on the local stress regime. Since the fabrics observed on the top of the slide deposits mimic the fabrics observed at the base (Fig. 10), it is interpreted that the remoulded material presented the same brittle behaviour, from top to bottom. This interpretation is reinforced by the fact that the discontinuities defining these fabrics propagated throughout the entire thickness of the slide deposits (Fig. 12). The change from one type of fabric to the other tends to be gradual and continuous, as if the imprinting of the fabric took place as an ongoing process where the fractures within the slow-moving material were adjusted and readjusted in response to the different stress regimes. Therefore, the Tampen Slide deposits should not have presented major changes of rheological proprieties, either laterally or vertically, and the major factor controlling the spatial configuration of the fractures seems to be the local stress regime.

The proposed mechanism for the formation of the discontinuities within the Tampen Slide deposits can be compared to the development of crevasses in a glacier, despite the rheological differences and without the lateral constraint from the valley glacier walls. In general, the flow direction of a glacier can be deduced from the crevasse distribution since every crevasse undergoes modification through time and space, either due to flow differences between the centre and the margin of the glacier or changes on the glacier stress regime (Nye, 1952). The study of glacier crevasses also revealed that they respond effectively to changes in the underlying morphology (Paterson, 1994). Slope changes are known to have superficial expression, and induce the development of extensional flow and/or compressional flow.

Taking this comparison further and assuming that the fractures on the remoulded material were essentially controlled by the local stress regime, the fabrics of the Tampen Slide deposits can be used as indicators of flow type and transport direction during the last stage of sliding. Therefore, the observation that the morphology of the sliding surface controlled the fabrics distribution (Fig. 11) appears to validate the hypothesis that the morphology of the sliding surface induced changes on the transport direction and mass flow behaviour.

Figure 13 presents the relationship between the fabrics observed in the Tampen Slide deposits and the transport of remoulded material across the Møre Topographic High. Knowing that Møre Topographic High represented an obstacle to the transport direction of the remoulded material, the distribution of the wispy fabric region D1 (Fig. 11) suggests the development of compression flow on the south-eastern edge of the Møre Topographic High (see SR1 and AM1 on Fig. 13). Once the remoulded material overcame the Møre Topographic High, arcuate terraces and sinuous ridges were developed suggesting a semi-cohesive extending flow resulting from downslope acceleration in the material translation (see SR2 on Fig. 13). On the western edge of the Møre Topographic High (Fig. 6), as the flow reached the erosive features of the preserved cauliflower-shaded headwall, the pattern of discontinuities was reshaped in response to the irregular underlying morphology. The principle stress $\sigma_{3}$ was possibly almost parallel to the flow direction near the centre of depressions, rotating the discontinuities at right angles to the flow direction. However, the stress pattern and consequently the resulting fabric were probably also influenced by the drag of the material above the ridges of the Møre Topographic High, developing a marked curvilinear fabric (see SR3 and AM3 on Fig. 13). Channelized by the 
erosive features on the western edge of the Møre Topographic High, the flow direction of the material above the topographic high appears to have been shifted westwards, forcing this material to join the flow that moved around the Møre Topographic High. The thinner deposits and the anastomosing fabric observed in the regions A1 and A2 (Fig. 7) suggest a relatively fast flow of remoulded material around the Møre Topographic High. Due to the difference in flow velocity, it is assumed that shear zones developed along the eastern margin of region A1 (see AM4 on Fig. 13).

From all of the information extracted from the seismic data, and by inferring the mass-flow behaviour from the distinctive fabric patterns recognised in the Tampen Slide deposits, an interpretative map of the material transported during the last stages of remobilisation has been compiled (Fig. 14). This map highlights changes in the direction of transport, inferred relativevelocities of transport, and type of flow. The inferred transport direction generally ranging from NNW to NNE throughout the study area, but immediately downslope of the Møre Topographic High the flow seems to have diverted from NNW to W. The fastest rate of mass flow probably occurred westward of the Møre Topographic High along the A1 region, whereas the slowest rate of mass flow probably occurred immediately downslope of the Møre Topographic High. Compressive and extending flows developed in response to velocity changes and shear zones developed in response to the variation in transport velocity between the different areas of the mass flow. The morphological changes on the Tampen's sliding surface, especially the presence of the Møre Topographic High, played a major role in the distribution of the slide deposits, fabric development and mass flow behaviour (Fig. 14).

\section{Conclusions}

The study of 3D seismic data from the northern flank of the North Sea Fan revealed recognizable internal structure within the Tampen Slide deposits, defined by penetrative acoustic discontinuities identified by their low-amplitude values. These discontinuities within the remoulded material define different fabrics, recognisable in both horizon and windowed amplitude map, as well as in spatial analysis maps generated from the slide top surface. The transition from one fabric to the other tend to be gradual and continuous.

The internal structure of the remoulded material depends on: 1) the stress regime, 2) the mechanical properties of the remoulded sediment and, 3) the morphology of the underlying surface. These are controlled by a combination of various factors including: the dynamics of the mass movement (velocity, thickness, interaction with the underlying surface), variations in the nature of the remoulded material (lithology, porosity, fluid saturation, cohesion) and the characteristics of the underlying morphology (slope, aspect, smoothness). Variations in the morphology of the underlying sliding surface, especially the presence of the Møre Topographic High, appear to be the principal control of the fabric distribution and deposits' internal structure within the studied Tampen Slide deposits. The recognised internal structure within the slide deposits can be considered as kinematic indicators and thought to have developed during the last stages of mass transport.

The identification of acoustic patterns within deposits that are normally described from 2D seismic as chaotic or acoustically transparent highlight the potential of detailed analysis of 3D seismic data. And, it gives an example of how this source of data, gradually more available, can provide new insights into the mechanisms and processes associated with gravitational collapses. 


\section{Acknowledgements}

The authors are grateful to StatoilHydro for providing the 3D seismic and bathymetric data and giving permission to publish. The Portuguese Foundation for Science and Technology (FCT) sponsored the contribution of the first author. J. Gafeira, D. Long and D. Evans publish with permission of the Executive Director of the British Geological Survey (NERC). The authors would like to also express their gratitude to two anonymous reviewers whose thoughtful insights and suggestions helped to improve the manuscript significantly.

\section{References}

Bryn, P., Solheim, A., Berg, K., Lien, R., Forsberg, C. F., Haflidason, H., Ottesen, D. \& Rise 2003. The Storegga Slide complex; Repeated large scale sliding in response to climatic cyclicity. In: L. Locat, J. \& Mienert, J. (ed.) Submarine Mass Movements and their Consequences, Klumer Academic Publishers, 215-222.

Bull, S., Cartwright, J., \& Huuse, M. 2009. A review of kinematic indicators from mass-transport complexes using 3D seismic data. Marine and Petroleum Geology, 26, 1132-1151.

Dahlgren, K. I. T., Vorren, T. O., Stoker, M. S., Nielsen, T., Nygård, A. \& Sejrup, H. P. 2005. Late Cenozoic prograding wedges on the NW European continental margin: their formation and relationship to tectonics and climate. Marine and Petroleum Geology, 22, 1089-1110.

Evans, D., King, E. L., Kenyon, N. H., Brett, C. \& Wallis, D. 1996. Evidence for long-term instability in the Storegga Slide region off western Norway. Marine Geology, 130, 281-292.

Evans, D., Harrison, Z., Shannon, P. M., Laberg, J. S., Nielsen, T. \& Ayers, S. 2005. Palaeoslides and other mass failures of Pliocene to Pleistocene age along the Atlantic continental margin of NW Europe. Marine and Petroleum Geology, 22, 1131-1148.

Frey-Martinez, J., Cartwright, J. \& James, D. 2006. Frontally confined versus frontally emergent submarine landslides: A 3D seismic characterization. Marine and Petroleum Geology, 23, 585-604.

Gafeira, J., Bulat, J., \& Evans, D. 2007. The Southern Flank Of The Storegga Slide: Imaging And Geomorphological Analyses Using 3D Seismic. In V. Lykousis, D. Sakellariou, \& J. Locat, Submarine Mass Movements and Their Consequences:3rd International Symposium, Advances in Natural and Technological Hazards Research, 27, 5765.

Gee, M. J., Gawthorpe, R. L., \& Friedmann, J. S. 2005.Giant striations at the base of a submarine landslide. Marine Geology, 214, 287-294.

Huvenne, V. A. I., Croker, P. F. \& Henriet, J. 2002. A refreshing 3D view of an ancient sediment collapse and slope failure. Terra Nova, 14, 33-40.

King, E. L., Haflidason, H., Sejrup, H. P. \& Lovlie, R. 1998. Glacigenic debris flows on the North Sea Trough Mouth Fan during ice stream maxima. Marine Geology, 152, 217-246.

King, E. L., Sejrup, H. P., Haflidason, H., Elverhoi, A. \& Aarseth, I. 1996. Quaternary seismic stratigraphy of the North Sea Fan: glacially-fed gravity flow aprons, hemipelagic sediments, and large submarine slides. Marine Geology, 130, 293-315.

Norwegian Deepwater Programme (NDP) 2004. Mid- to Late Cenozoic Geomodel of the Mid-Norwegian Continental Margin. Seabed Project Phase II - Model Volume. Report no. SP2-02-FS-01R-00001-04 compiled by Fugro Survey Limited, 108pp.

Nye, J. F. 1952. The mechanics of glacier flow. Journal of Glaciology, 2, 82-93.

Nygård, A., Sejrup, H. P., Haflidason, H. \& Bryn, P. 2005. The glacial North Sea Fan, southern Norwegian Margin: architecture and evolution from the upper continental slope to the deep-sea basin. Marine and Petroleum Geology, 22, 71-8.

Paterson, W. S. B. 1994. The physics of glaciers Elsevier (ed.), Pergamon, 480 pp.

Sejrup, H., Haflidason, H., Hjelstuen, B. O., Nygård, A., Bryn, P. \& Lien, R. 2004. Pleistocene development of the SE Nordic Seas Margin. Marine Geology, 213, 169-200.

Strachan, L. J. 2008. Flow transformations in slumps: a case study from the Waitemata Basin, New Zealand. Sedimentology, 55, 1311-1332.

Vorren, T. O. \& Laberg, J. S. 1997. Trough mouth fans - palaeoclimate and ice-sheet monitors. Quaternary Science Reviews, 16, 865-881. 


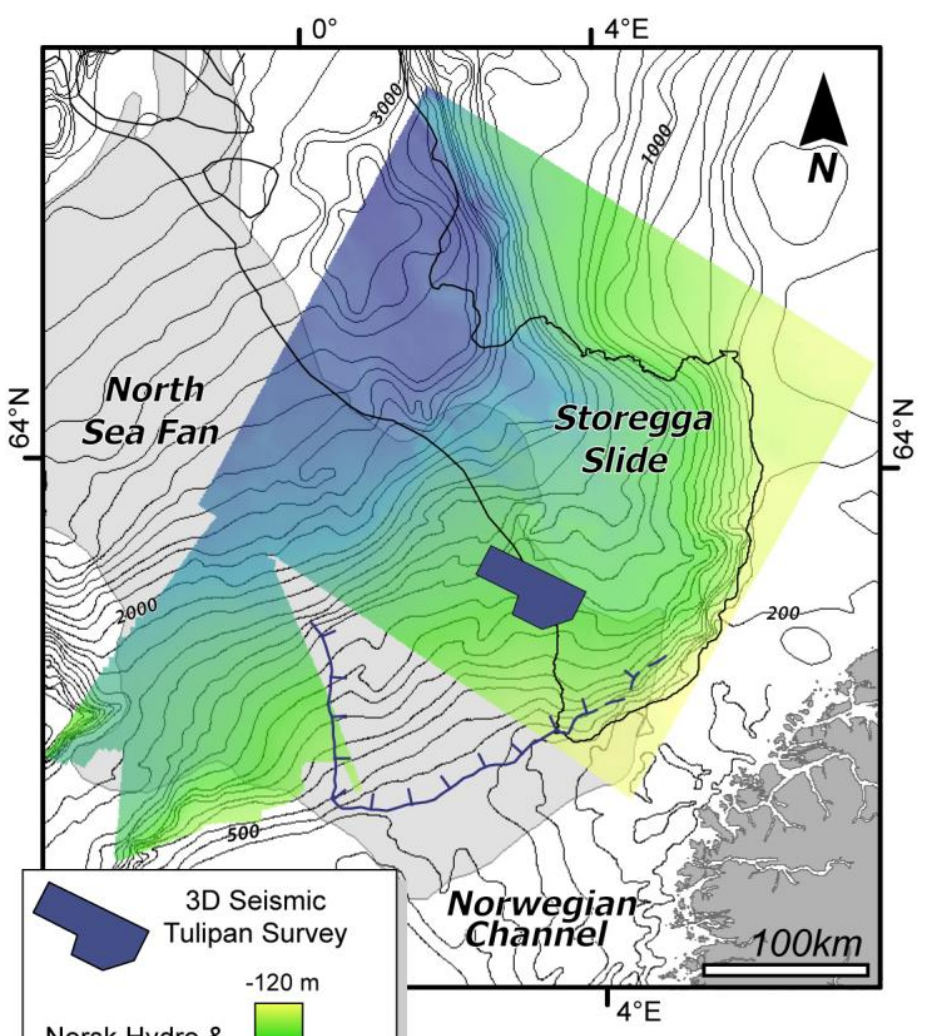

Norsk Hydro \&

SEA4 Bathy

Tampen Slide

$\perp \perp$ Observed scarp

__L_ Inferred scarp

Fig. 12

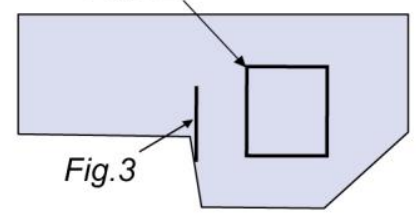

Fig. 1. Mid-Norwegian continental margin map, showing the location of the study area with the outline of the major gravitational collapse and extension of the North Sea Fan, the 3D seismic Survey (Tulipan), and Norsk Hydro and SEA4 bathymetry. The location of some figures is shown on the zoom in of the Tulipan survey situated on the bottom right corner of the figure. 


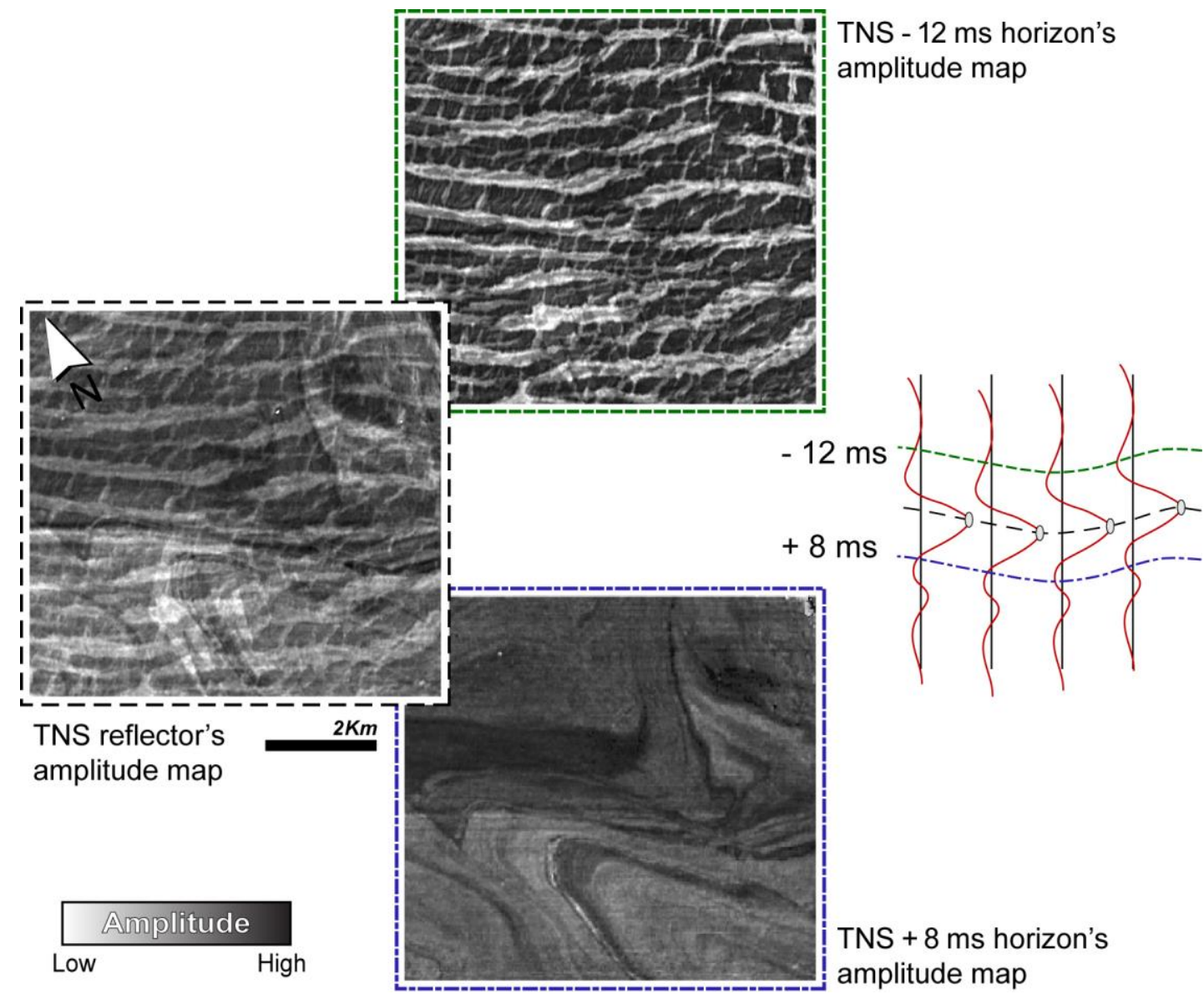

Fig. 2. Example of the extraction of multiple amplitude maps from the TNS picked horizon. The amplitude maps from above (TNS $-12 \mathrm{~ms}$ ) and beneath (TNS $+8 \mathrm{~ms}$ ) the key reflector show distinct and well defined acoustic patterns while the amplitude map of the TNS itself shows complex patterns overlying information from above and beneath. The sketch on the right shows the position of the TNS' sub-horizons in relation to hypothetical wave-traces

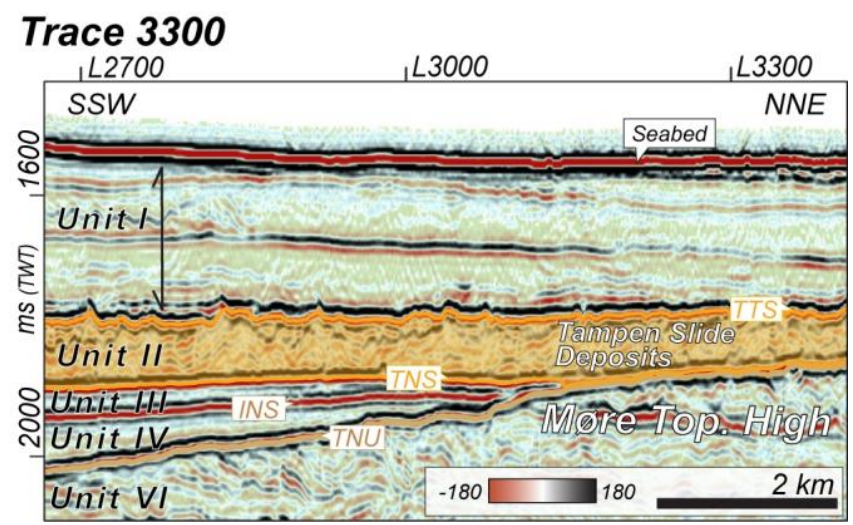

Fig. 3. Cross section from the 3D seismic volume through the Møre Topographic High showing the Tampen Slide deposits at the contact between the top of Unit III and the top of the Møre Topographic High. The Tampen Slide deposits are highlighted in orange and delineated by the reflectors TTS and TNS. Location shown in Fig. 1. 


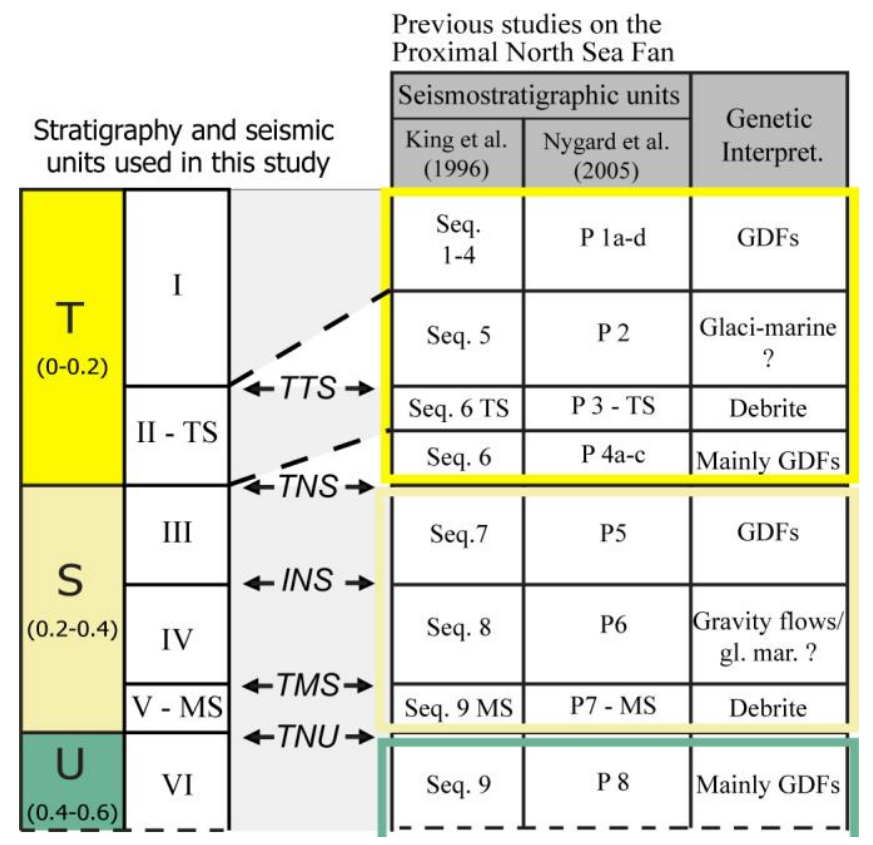

Fig. 4. Correlation between stratigraphy and seismic units used in this study and previous studies. The Naust sequences nomenclature used is from the Seabed Project (Norwegian Deepwater Programme , 2004). TS: Tampen Slide; MS: Møre Slide. Key reflectors: TTS (top of the Tampen Slide); TNS (top of Naust S); INS (Naust S internal reflection); TMS (top of the Møre Slide); TNU (top of Naust U).

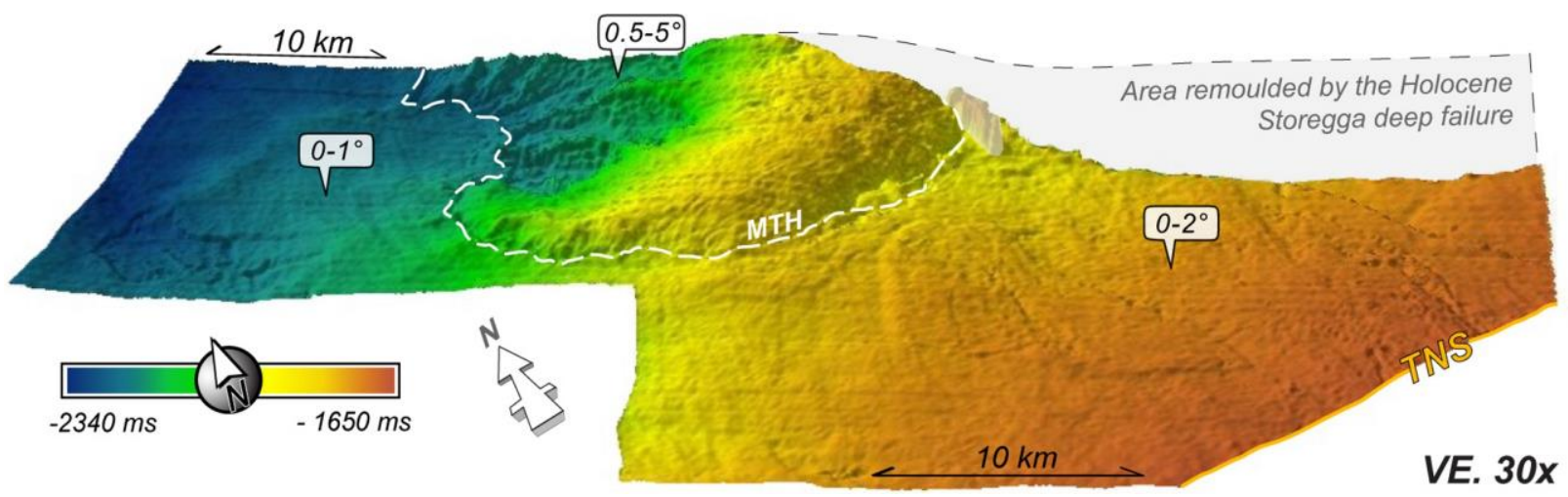

Fig. 5. 3D perspective view from SSE of the Tampen Slide's sliding surface - reflector TNS. The dashed white line marks the contact between the top of Unit III and the Møre Topographic High (MTH). Note the gradient change from the surroundings areas to the Møre Topographic High. The area in grey corresponds to the area disturbed by the Storegga Slide where it is impossible to track the TNS reflector. 


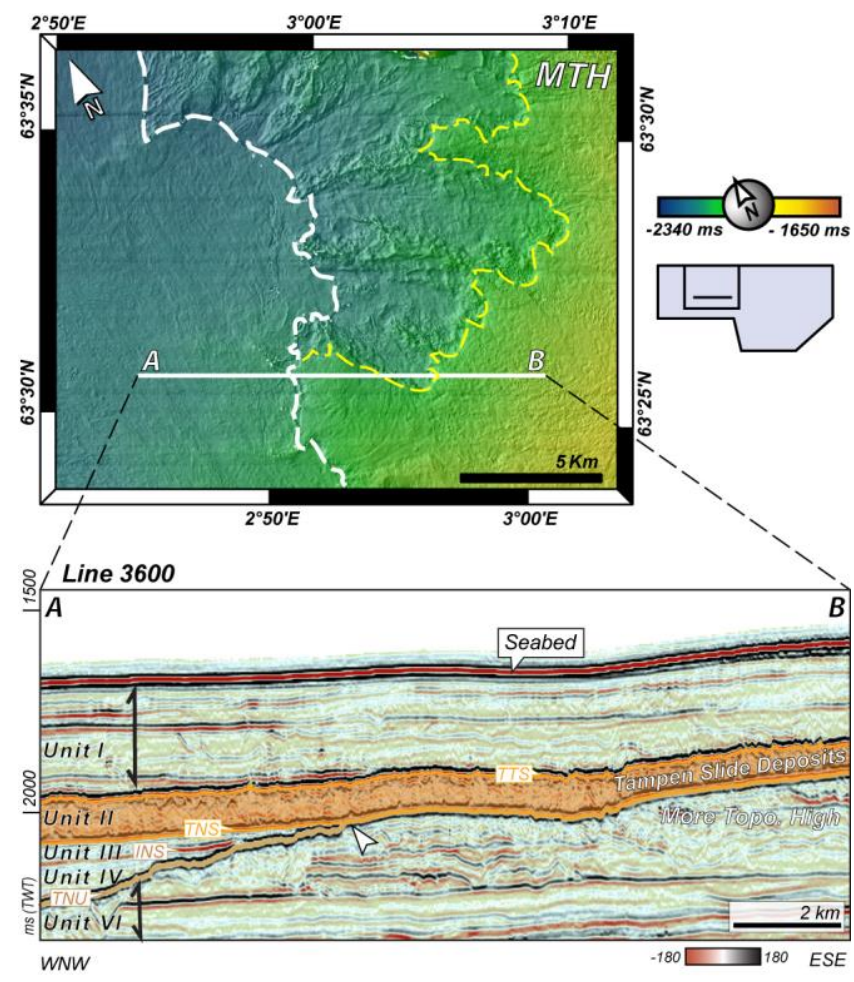

Fig. 6. (Top) Detail of the shaded-relief map of TNS, showing the cauliflower-shaped headwall on western edge of the Møre Topographic High and location map. The yellow dashed line marks the uppermost scar area, whereas the white line marks the contact between the top of Unit III and the Møre Topographic High. (Bottom) Cross-section from the 3D seismic volume through the western edge of the Møre Topographic High. Arrow points the contact between the top of Unit III and the Møre Topographic High.

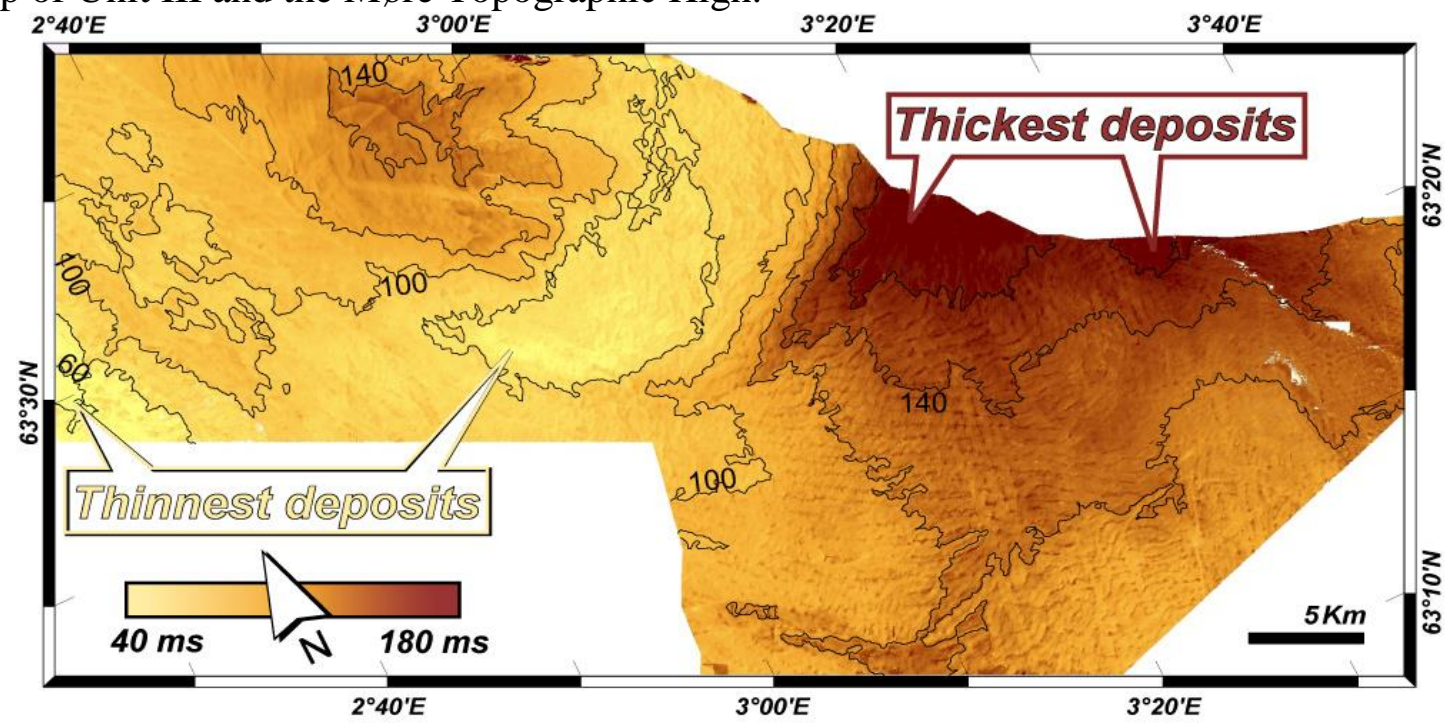

Fig. 7. Isochron map of the Tampen Slide deposits, calculated from TNS and TTS reflector time values. Contour lines every $20 \mathrm{~ms}$. 


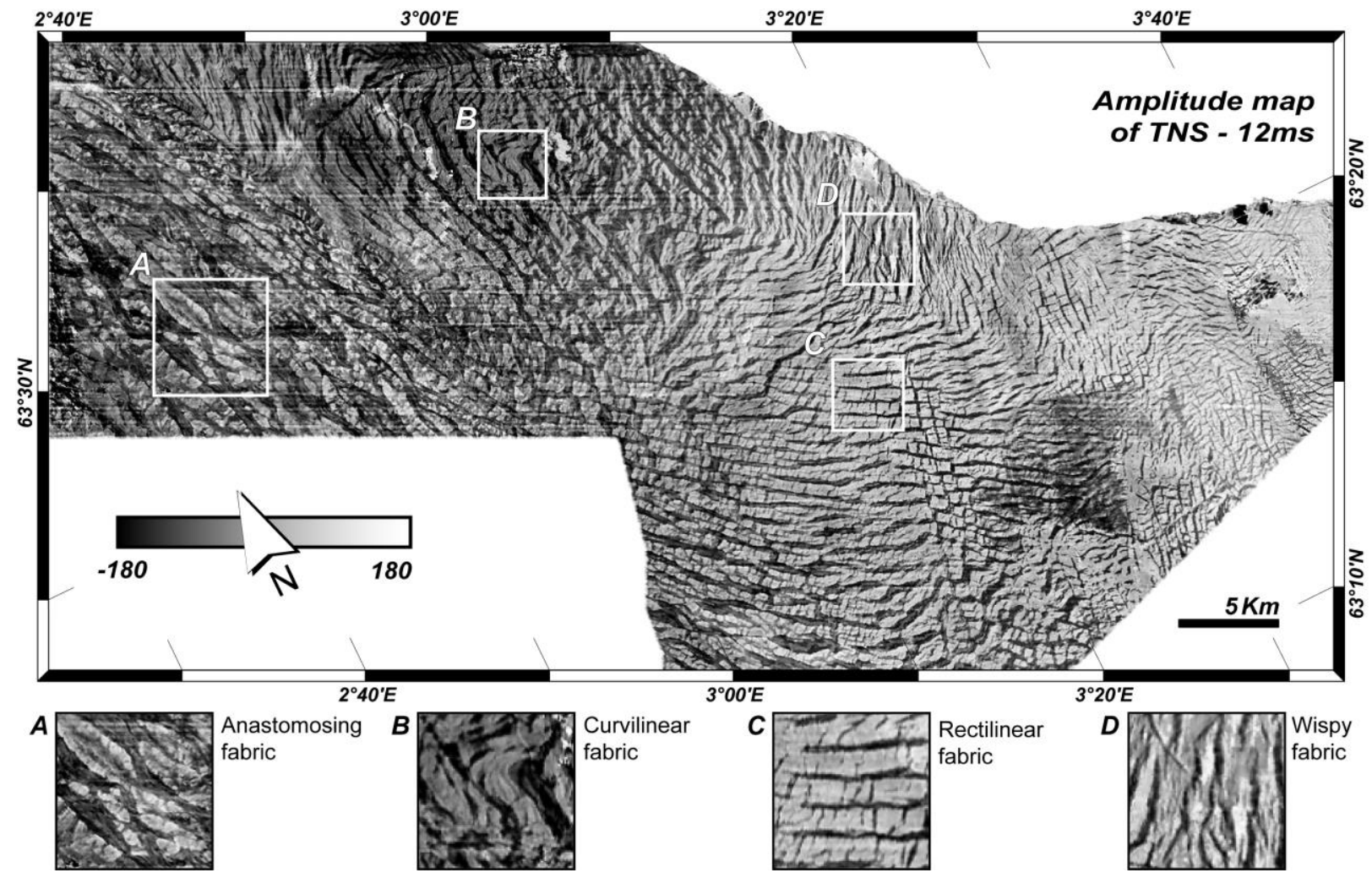

Fig. 8. Amplitude map of the horizon TNS-12ms showing the overall distribution of the amplitude patterns observed $12 \mathrm{~ms}$ above the base of the Tampen Slide deposits. Detailed views of the main recognised fabrics: (A) Anastomosing fabric, (B) Curvilinear fabric, (C) Rectilinear fabric, and (D) Wispy fabric. 

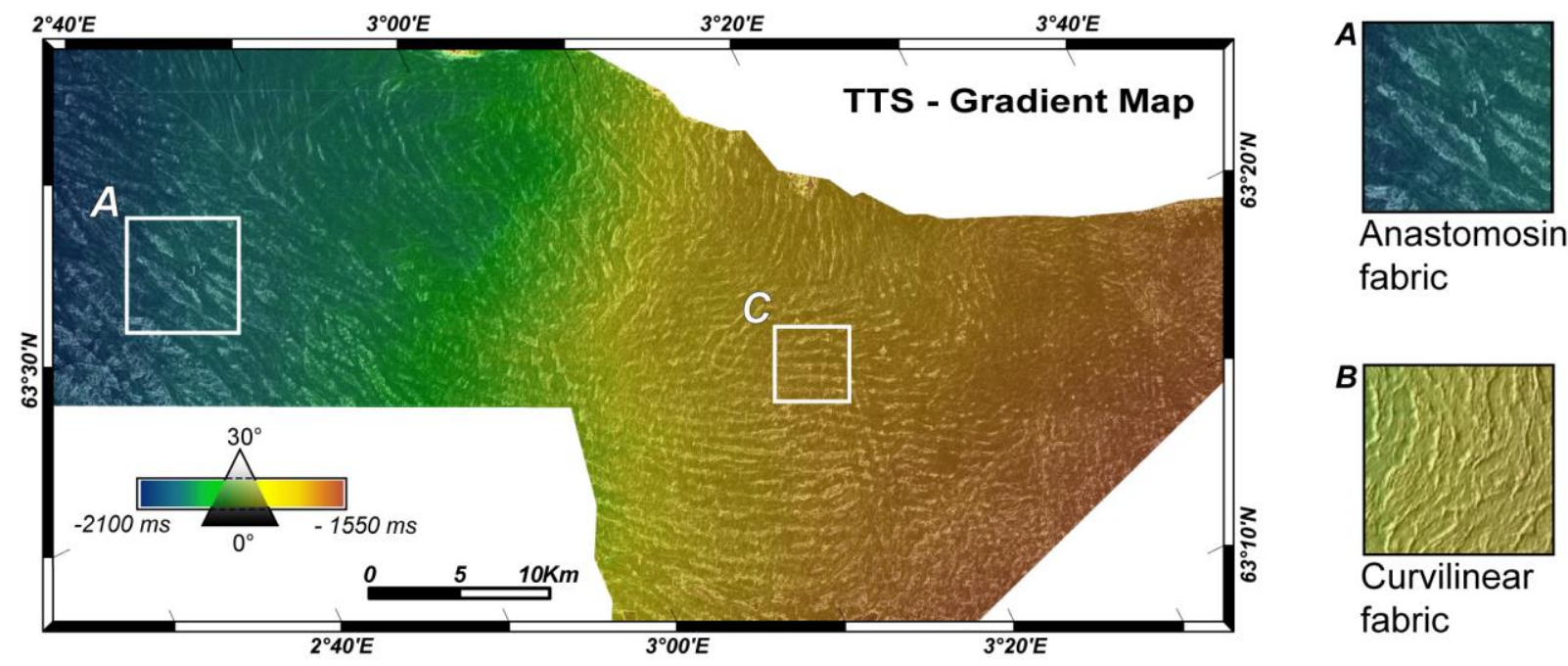

Anastomosing

fabric
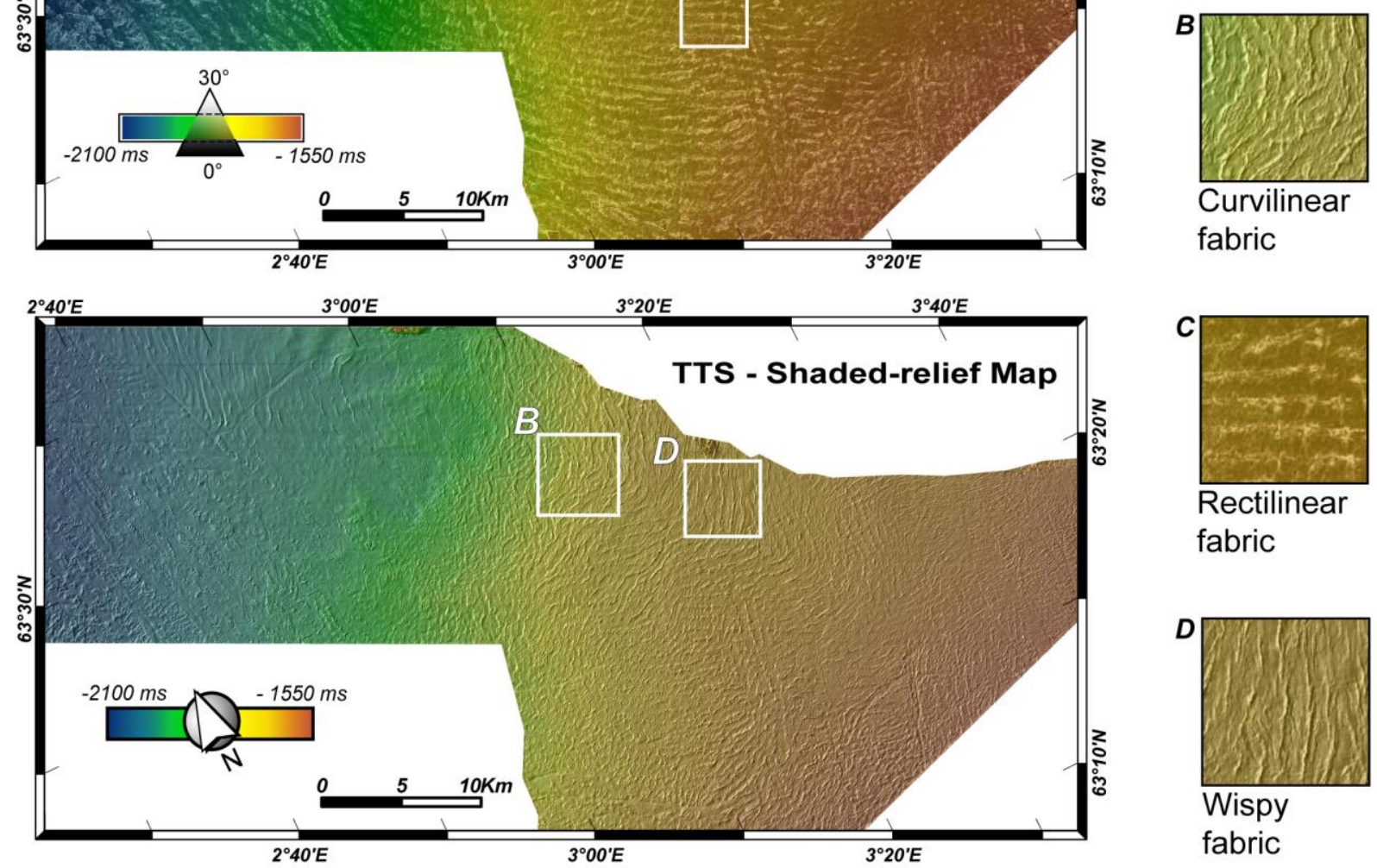

Rectilinear

fabric

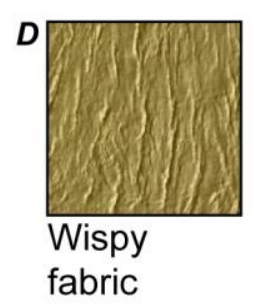

Fig. 9: (Top) Gradient and depth map of the top of the Tampen Slide deposits obtained from the TTS reflector. The brightness shows the gradient with low slope values in black and higher slope values in white, here white corresponds to slope higher than $30^{\circ}$. (Bottom) Shaded-relief map of TTS with artificial illumination from northwest at $45^{\circ}$. The colour-scale shows the depth in ms (TWT) in both maps. Note that texture of the top surface of the Tampen Slide deposits varies from zone to zone and some textures are more visible in one or the other map. (Right) Detailed views of the main recognised fabrics: (A) Anastomosing fabric, (B) Curvilinear fabric, (C) Rectilinear fabric, and (D) Wispy fabric. 


\begin{tabular}{|l|l|} 
& $\begin{array}{l}\text { Anastomosing } \\
\text { Top: Lenticular blocks defined by relative steep edges } \\
\text { surrounded by gaps, with gentler surface, which branch } \\
\text { out and reconnect. } \\
\text { Base: Higher amplitude blocks delineated by lower } \\
\text { ampl. stripes that reconnect after initial branching out. }\end{array}$ \\
\hline SR & $\begin{array}{l}\text { Curvilinear } \\
\text { Top:Arcuate terraces with relative steep edges changing } \\
\text { to discontinuous sinuous ridges downslope. } \\
\text { Base: Broken curvilinear higher amplitude stripes } \\
\text { separated by narrower lower amplitude stripes. }\end{array}$ \\
\hline SG & $\begin{array}{l}\text { Rectilinear } \\
\text { Top: Straight, discontinuous, parallel ridges with smaller, } \\
\text { perpendicular ridges. } \\
\text { Base: } \text { Rectilinear higher amplitude blocks delineated by } \\
\text { straight, parallel lower amplitude stripes and less } \\
\text { pronounced perpendicular stripes. }\end{array}$ \\
\hline SR & $\begin{array}{l}\text { Wispy } \\
\text { Top: Bifurcated thin ridges that become diffused at the } \\
\text { edge. } \\
\text { Base: } \\
\text { become thinner and difuse at the edge. }\end{array}$ \\
\hline
\end{tabular}

Fig. 10. Fabric classification used in this study to describe the patterns observed within the Tampen Slide deposits, based on a combination of spatial analysis generated maps from the top of the Tampen Slide deposits (SR - detail of the shaded-relief map, SG - slope gradient map) and the amplitude map (AM) of the reflector TNS at the base of this deposits.

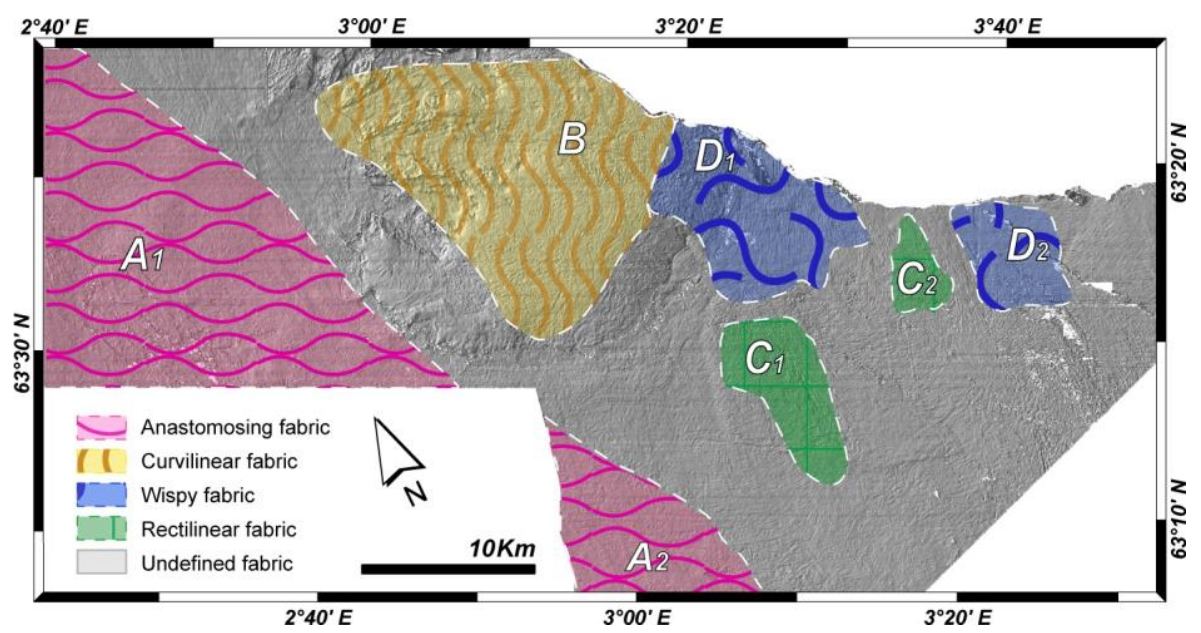

Fig. 11. Distribution map of the seven fabric regions (A1, A2, B, C1, C2, D1 and D2) identified on the Tampen Slide deposits overlying the shaded-relief map of the TNS reflector that correspond to the base of the Tampen Slide deposits. 


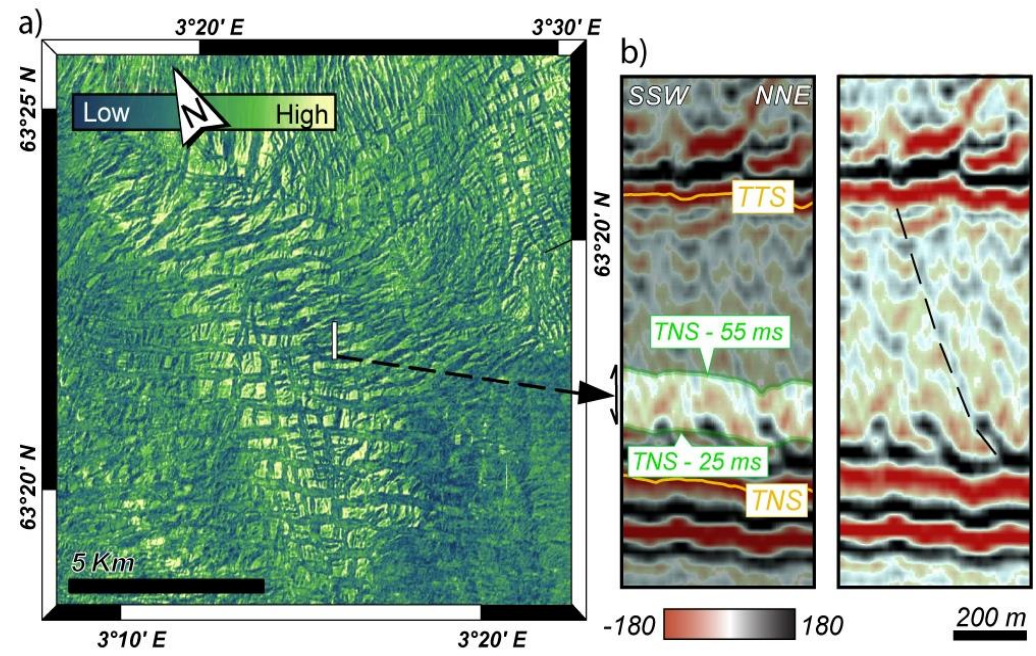

Fig. 12. a) RMS amplitude map of the $C 1$ area, for a $30 \mathrm{~ms}$ window centred $40 \mathrm{~ms}$ above the reflector TNS. b) Detail view of the Tampen Slide deposits on seismic cross-section cutting through part of $\mathrm{C} 1$ area. On the left, the image shows the depth window used for the RMS amplitude map. On the right, the dashed line shows an example of the link between the thrusts at the base of the deposits and the topographic irregularities of the top of the deposits.

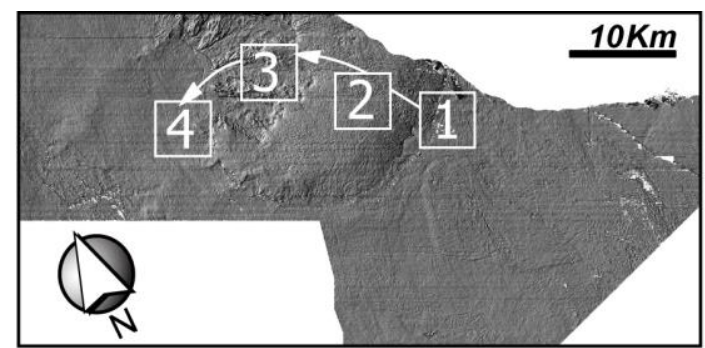

SR 1

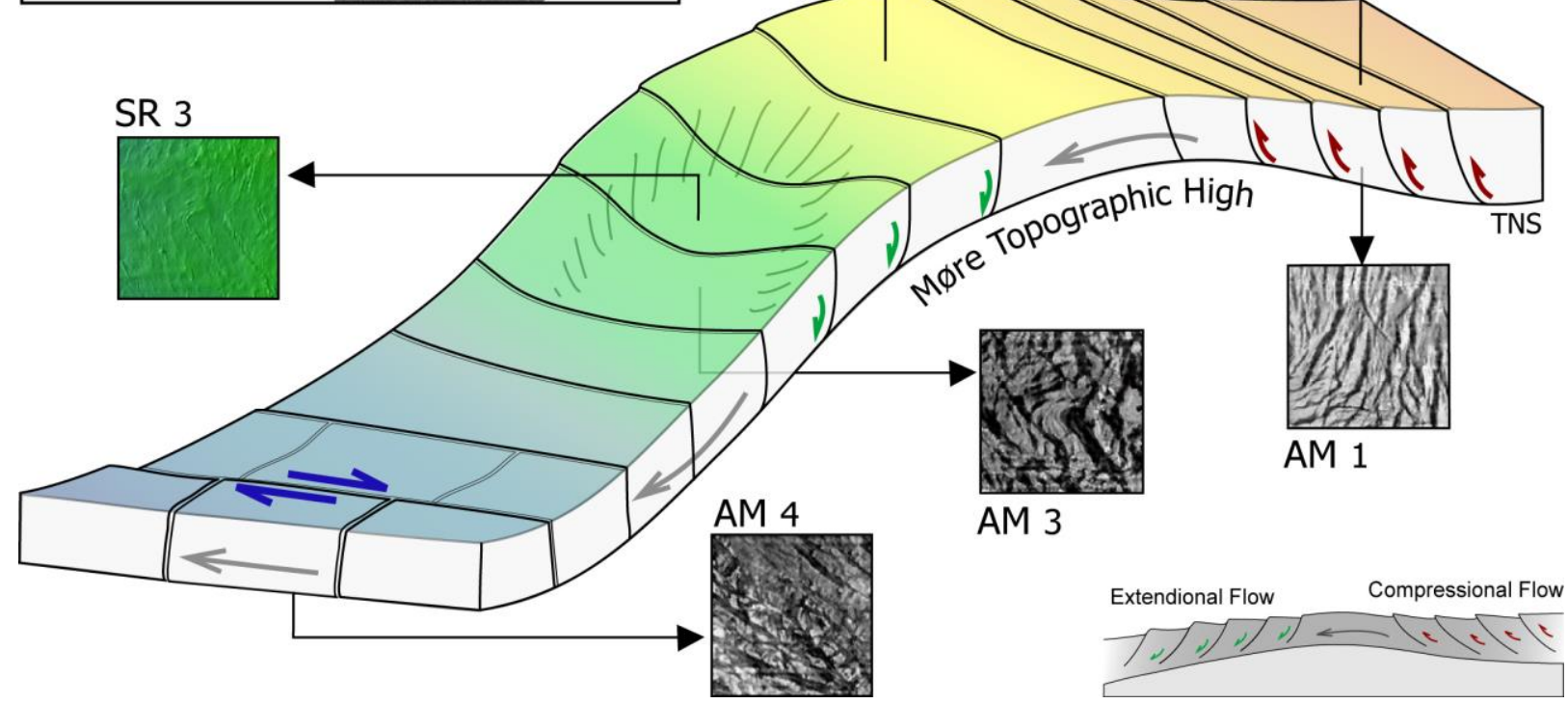

Fig. 13. Graphic representation of the relation between the fabrics observed on the Tampen Slide deposits and the inferred mass flow behaviour across the Møre Topographic High. Arrows show the direction of transport and relative movement within the flow. Note the curved trajectory of the remoulded material controlled by the morphology of the Møre Topographic High. $S R$-images show details of the shaded-relief map of the TTS surface and $A M$-images 
show details of the amplitude map of TNS-12ms horizon; the numbers 1,2, 3, and 4 refer to their respective positions on the upper left corner map.

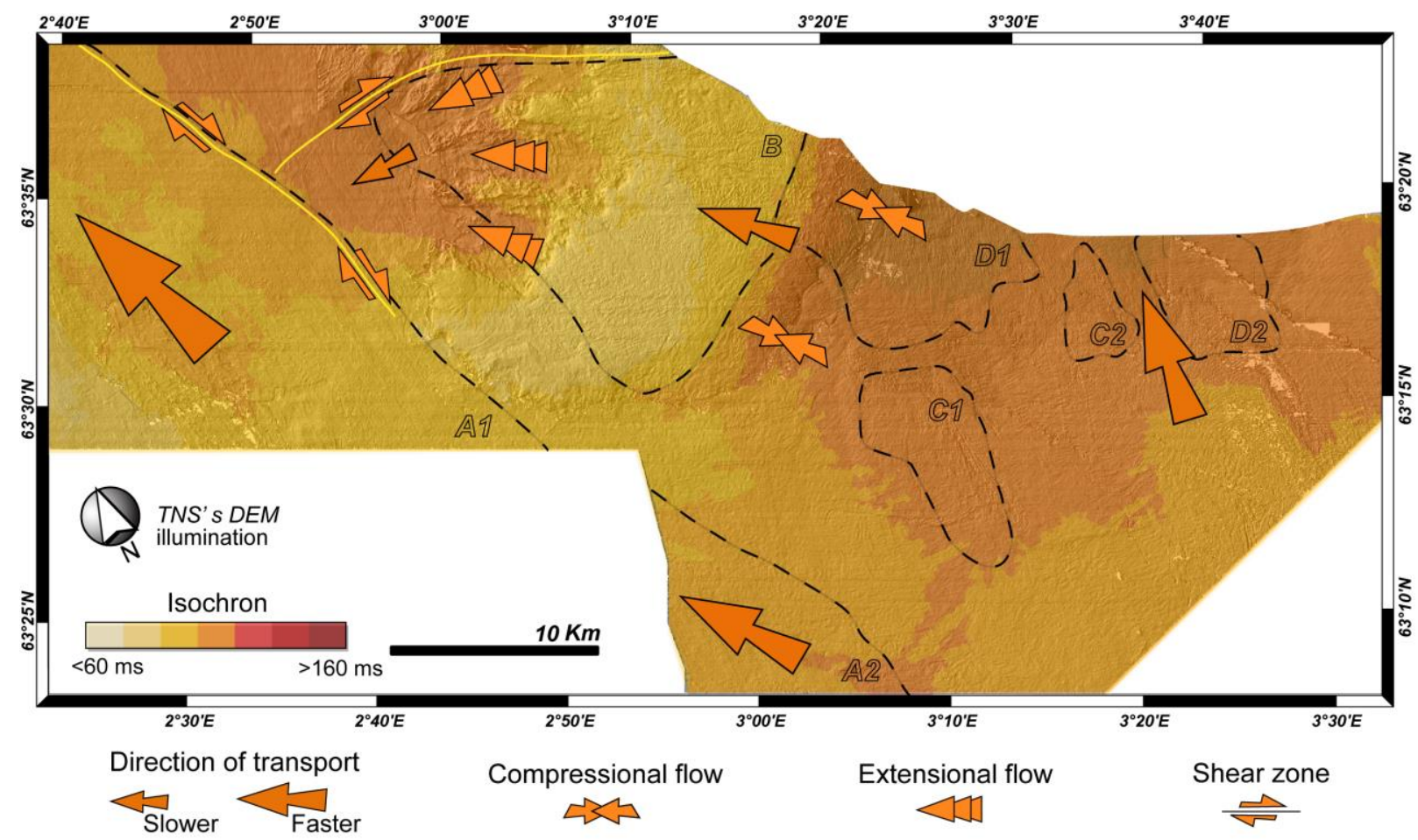

Fig. 14. Interpretative map of the Tampen Slide deposits showing the main transport directions inferred from the seismic fabrics. The background of the map is the isochron of Tampen Slide and main fabrics overlaying the TNS reflector's shaded-relief map. Note that the size of the arrows showing the transport direction reflects their relative velocity. 